
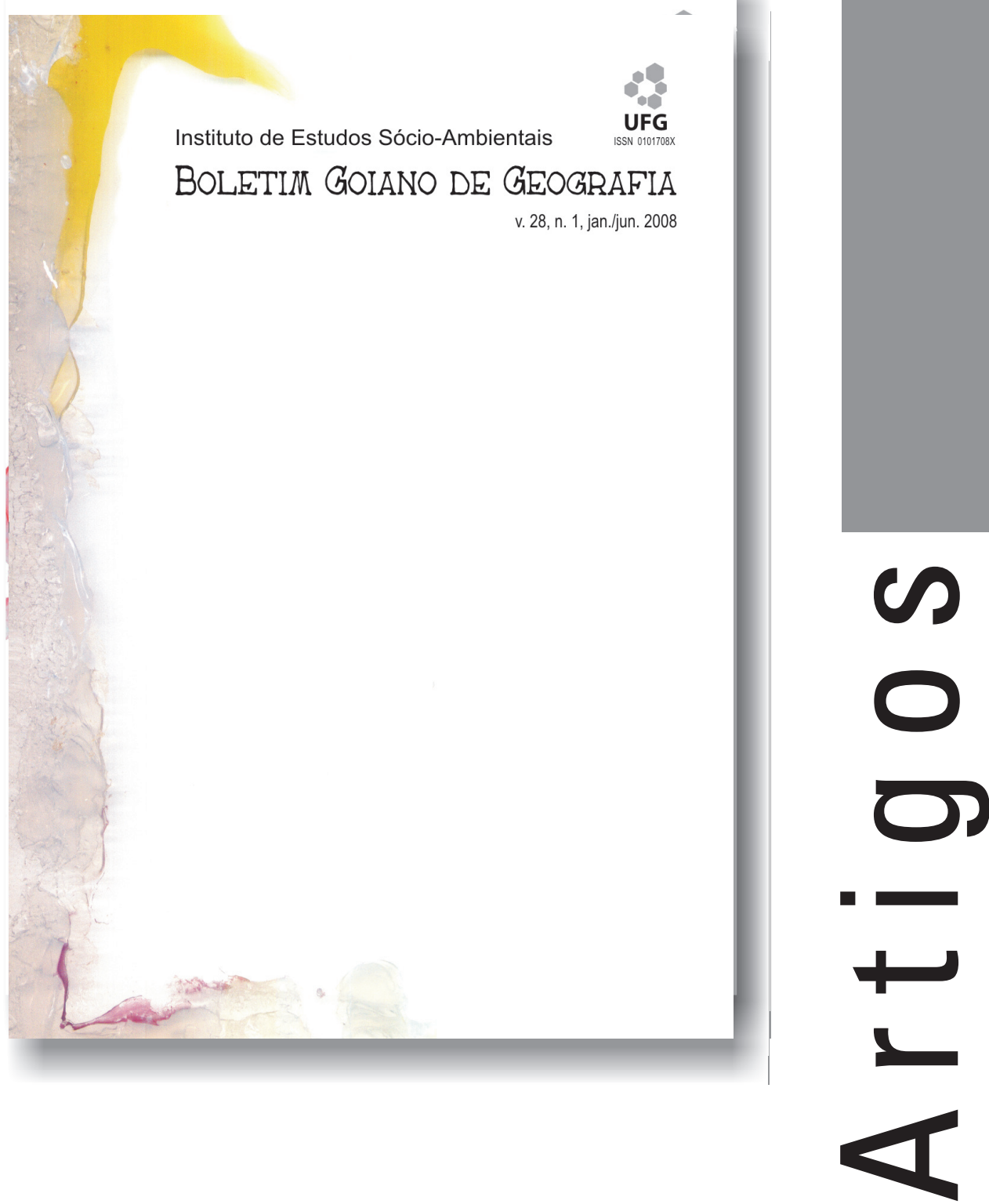


\title{
Espaço agrário brasileiro: exclusão e inclusão social
}

\author{
Brazilian agrarian space: social exclusion and inclusion
}

Helena Angélica de Mesquita - Universidade Federal de Goiás / CAC

helena@wgo.com.br

\section{Resumo}

Este texto traz algumas reflexões acerca do espaço agrário brasileiro, espaço este marcado por grandes conflitos e lutas de resistências das populações excluídas do processo sócio-econômico. É uma luta desigual em todos os sentidos, inclusive no registro pela história oficial, que ignora as lutas do povo e não reconhece os lutadores populares.

Palavras-chave: exclusão social; campesinato; latifúndio

\section{Abstract}

This text brings some analysis upon the Brazilian agrarian space. This space is featured by intense disputes and resistance fights taken by a part of the population excluded from the social and economical process. It is an unequal fight in all levels considered. Even the official historical record underestimate the people's fight and does not recognize the brave fighters emerged from the people.

Key-words: social exclusion; peasantry; land concentration 
$\cdots$

No lugar que havia mata,

home há perseguição

${ }^{1}$ Grileiro mata posseiro

só pra lhe roubar seu chão

Castanheiro, seringueiro já viraram até peão

afora os que já morreram como aves de arribação

Zé de Nana tá de prova

naquele lugar tem cova,

gente enterrada no chão

Pois mataram o índio, que matou grileiro

que matou posseiro

disse o castanheiro para o seringueiro

que o estrangeiro roubou seu lugar...

Vital Farias $^{l}$

\section{Introdução}

Na virada do III milênio, cinco séculos do “descobrimento" da América e do Brasil. O tempo passou, mas não passaram os massacres contra os trabalhadores, os meninos de rua e meninos do campo. Não bastara o sofrimento impingido a eles pelo salário mínimo, más condições de vida e desemprego puro e simples, ainda são protagonistas de episódios como os da Candelária, Carandiru, Eldorado do Carajás, Corumbiara, Favela Naval e tantos outros locais que serviram de palco para massacres e execuções. As respostas do governo quando é chacoalhado por um episódio violento é anunciar medidas paliativas, tais como, aumentar a repressão com mais armamento para a polícia, aumentar os efetivos militares, treinar melhor os policiais, a reduzir a idade de responsabilidade criminal, e aventa-se até a possibilidade de pena de morte, enquanto as pessoas que podem, circulam em carros blindados e se escondem em fortalezas de muros e alarmes.

O Brasil figura tristemente entre os países de maiores diferenças sociais. Num país com tais condições sociais, qualquer política de natureza repressiva terá pouca eficácia. Criminalizar meninos de rua e sem terra, além de ser um exemplo de política medíocre, não resolve os problemas. 
As ações das populações reprimidas e excluídas são classificadas como subversão da ordem. Este estado de coisas tem como uma das causas a questão agrária não resolvida. Questão agrária no sentido mais amplo, que vai além da própria reforma agrária, que, no dizer de José de Souza Martins $^{2}$, seria a solução da questão, daquela que diz respeito às terras dos índios, dos posseiros, dos seringueiros, assim como às políticas agrícolas e agrárias, e até mesmo ambientais, que acabam por privilegiar o latifúndio em detrimento de grande parcela de trabalhadores que são excluídos, inclusive, do acesso à terra de trabalho. E os trabalhadores têm uma compreensão clara desta situação, como mostra o depoimento de um sem terra de Rondônia:

Os fazendeiros querem a gente sem terra para a gente ser empregado deles, ser peão, ser escravo ou quase escravo nas fazendas. Querem a gente trabalhando para eles ficarem cada vez mais ricos, mais poderosos e nós trabalhando para comprar comida para os filhos. A gente não quer comprar o nosso arroz, o nosso feijão, a gente quer ver a lavoura crescer e os filhos crescer também. A gente quer ir para a roça, para a nossa roça, ajudado pelos filhos, pela esposa, trabalhando todos juntos e voltando para casa juntos. E a família trabalhando unida, vivendo unida. Isso é tudo que a gente quer. Mas primeiro a gente precisa ter a terra... (Quebra-Mola. Ji Paraná - 30/09/97)

A história tem mostrado que os desterrados e desterritorializados têmse organizado e enfrentado esta estrutura secular de dominação e espoliação. Os camponeses têm conseguido romper este cerco e, de certa forma, colocar a questão em evidência.

No governo FHC, os meios de comunicação notificaram que a reforma agrária foi feita porque assentou um número grande de famílias. Mas segundo o professor Dr Bernardo Mançano Fernandes ${ }^{3}$, os assentamentos não se constituem em reforma agrária, porque, em sua maioria, são criados a partir de ocupações promovidas pelos camponeses, e então o governo é forçado a agir. Das 299.332 famílias assentadas no governo FHC, $256.467^{4}$ são famílias que ocuparam terras. E os assentamentos, apesar de necessários e muitas vezes eficientes, não alteram o poder dos latifundiários, porque a estrutura básica dos latifúndios continua intocada e intocável.

Se o governo FHC "promoveu" a reforma agrária, por outro lado aumentou as dificuldades dos pequenos produtores e reduziu os empregos no campo, e o que é mais grave, a repressão aos movimentos dos trabalhadores foi muito mais pronta e ferrenha. Mesmo assim, cresceram as reivindicações e protestos. Novos movimentos surgiram nas cidades e no campo eviden- 
ciando a resistência do povo. O que isso significa em termos de repensar a questão agrária e a reforma agrária no Brasil?

Novas e eficazes políticas de acesso à terra precisam ser implementadas urgentemente. Não se pode empurrar meninos e meninas para as "Candelárias” da vida. É mais humano, mais econômico e mais cristão desapropriar as "Santa Elinas" do Brasil e assentar esses "guerreiros", possibilitando a eles as condições para se tornarem cidadãos.

\section{História do campo brasileiro: algumas considerações}

As atividades agrícolas e agrárias compõem um setor importante da economia que não é necessariamente absorvido pelo processo de industrialização. Há várias correntes de análise sobre o campo, no Brasil, que consideram a agricultura subordinada ao processo industrial, principalmente porque o modelo desenvolvimentista implantado no país se "expande" ao campo, e uma dessas vias de expansão foi o Estatuto da Terra de 1964, que previu a transformação das unidades agrícolas em empresas rurais. A transformação em muitos casos, do proprietário da terra em empresário rural, segundo Martins (1986, p. 69), não suprime a contradição que a terra representa no desenvolvimento capitalista.

Embora o centro da economia capitalista esteja na indústria, a agricultura é relevante, assim como o seu estudo, porém precisa ser considerada em suas especificidades. É necessário estudar o campo e o campesinato que, segundo Martins (1996), é o lado moderno e revolucionário, enquanto o latifúndio é o lado atrasado e arcaico da estrutura econômica, social e política no Brasil.

Muitos estudiosos seguem a teoria clássica do ponto de vista da expansão do capitalismo no campo, com a consequënte homogeneização das relações de produção, e consideram o campesinato como algo do passado, pois o processo de diferenciação gerou a proletarização inexorável de todos os que não puderam ou não quiseram bancar os custos do processo de modernização. Dentro de tal concepção do processo de penetração da modernização, a proletarização seria resultado do próprio mercado, que se encarregaria de excluir o camponês do processo produtivo. Os latifúndios então não "precisam" desaparecer, desde que assumam o caráter capitalista, ou seja, modernizem os latifúndios.

O pressuposto histórico desta e de outras tendências é o desaparecimento do campesinato, pois os camponeses entrariam num processo de 
diferenciação, se tornando pequenos capitalistas ou se proletarizando. Tais tendências parecem esbarrar na realidade brasileira que está a evidenciar o recrudescimento de latifúndio e a criação e recriação do campesinato, com a expansão do campo de lutas e resistência.

Os processos recentes de transformação permitem, em muitos casos, que o proprietário de terra e o capitalista sejam unificados, pois lhes permitem obter lucro e renda fundiária. Então, se por um lado recriam as condições para expansão do latifúndio, pelo outro, contraditoriamente, criam e recriam o campesinato, ou seja, uma classe em oposição ao latifundiário.

É o campesinato que quer entrar na terra, que ao ser expulso, com freqüência à terra retorna, mesmo que seja terra distante daquela de onde saiu. O nosso campesinato é constituído com a expansão capitalista, como produto das contradições dessa expansão. Por isso, todas as ações e lutas camponesas recebem do capital, de imediato, reações de classe: agressões e violências, ou tentativas de aliciamento, de acomodação, de subordinação. (MARTINS, 1986, p. 16).

Esta análise está mais próxima da realidade brasileira, e vem procurando explicações para a permanência do campesinato, pois segundo Martins, o próprio capitalismo cria e recria as relações não capitalistas de produção. É a ampliação da produção camponesa combinada ou não dentro da contradição capitalista. O campesinato e o latifúndio devem ser compreendidos dentro do capitalismo, e não fora dele. (OLIVEIRA, 1986, p. 11).

Para se compreender que tais pressupostos são mais compatíveis com a realidade brasileira, basta ver os sujeitos sociais e políticos que se apresentam como a UDR, o MST, os posseiros, os índios, os grileiros, os colonos, os latifundiários, os ruralistas etc., evidenciando que a questão é mais complexa do que parece.

No nosso caso, o avanço do capitalismo não dependeu da abertura de um espaço livre à ocupação de capital. O trabalhador já era expropriado. Foi o próprio capital que, com a crise do trabalho escravo, instituiu a apropriação camponesa da terra; uma contradição evidente num momento em que o capital necessitava de força de trabalho, de trabalhadores destituídos de sua própria força de trabalho. Por essa razão, o nosso camponês não é um enraizado. Ao contrário, o camponês brasileiro é desenraizado, é migrante, é intinerante. (MARTINS, 1986, p. 17).

O processo histórico é constituído pelas relações sociais, pelas relações e antagonismos de classe. Assim, para Martins, o campesinato brasileiro é resultado e conseqüência do próprio desenvolvimento capitalista no 
campo, e considera algumas questões como a sua resistência e formas de luta. As respostas às lutas e reivindicações camponesas têm sido sempre respostas e reações de classe, haja vista os conflitos mais intensos como Canudos, Contestado, Trombas e Formoso e, mais recentemente, Corumbiara e Eldorado do Carajás, assim como os conflitos permanentes pelo acesso e posse da terra são tensões, e estão onde estão as cercas do latifúndio. Os conflitos, em muitos casos, são resolvidos de maneira brutal. São conflitos de classes transformados em massacres contra os camponeses. Para entender tais questões, é preciso dialogar com as evidências e ultrapassar as aparências para compreender a realidade como expressão do exercício do poder, o poder de ocultar, excluir, esquecer, e o poder de mostrar e de não esquecer, o que seria um outro poder.

Os indígenas estão há quinhentos anos lutando, fugindo, morrendo e resistindo numa luta contra o capital, representado por jesuítas, por senhores de engenho, e hoje, por grileiros, madeireiros, latifundiários, com o apoio do Estado.

Se a Amazônia era o último refúgio dos povos indígenas (OLIVEIRA, 1996, p. 12), disse bem o autor "era”, porque, por exemplo, em Rondônia, os projetos de colonização dirigidos pelo INCRA não têm considerado os seus territórios. E embora tenha criado algumas "áreas de reserva indígena”, que são muito mais espaço de confinamento, tais áreas não são respeitadas e o massacre dos índios continua.

O índio, se não foi formalmente escravizado, foi e está sendo sistematicamente desterritorializado e, conseqüentemente, sendo exterminado, numa luta desigual, como a luta dos negros que chegaram ao Brasil na condição de escravos, ou seja, marginalizados "à priori” e constituíram a força de trabalho que moveu a colônia, como trabalhadores e, ao mesmo tempo, mercadorias. Os negros que entraram na história do país como excluídos, saem da mesma em 1888 com a Lei Áurea, mas não chegam a se tornar cidadãos, pois o que lhe garantiria tal possibilidade seria o acesso à terra. Qual terra, neste imenso território? A apropriação das terras já estava garantida aos senhores brancos e católicos, desde o tempo das capitanias hereditárias, sesmarias e legitimadas pela Lei de Terras de 1850. A Lei 601/1850 instituiu o que Martins chama de "Cativeiro da Terra" no momento da transição da mão-deobra escrava para a mão-de-obra livre, e segundo o mesmo autor, livre, não necessariamente assalariada, o que seria a lógica capitalista. A contradição se estabeleceu quando, para se reproduzir, o capital passou a utilizar-se da propriedade privada da terra e da renda que ela podia proporcionar. A mão- 
de-obra, por sua vez, precisava também corresponder à nova ordem mundial de expansão de consumo e produção de matérias-primas para as nações em processo de industrialização, e especialmente, para a nova potência que emerge na própria América e que também tinha sua lei de terras, mas com uma letra e um espírito muito diferentes de nossa legislação.

Emília Viotti da Costa, ao tratar destas questões ${ }^{6}$, analisa as diferenças e semelhanças no contexto da lei de terras brasileira e norte-americana, e evidencia, que no Brasil as forças mais conservadoras foram as que articularam e criaram o que lhes garantiu o poder sobre a terra, poder da terra e o poder sobre o poder, e ao mesmo tempo, garantiu mão-de-obra, inicialmente mesmo escrava, com a possibilidade de manejo dos "estoques" de escravos de uma região para outra, assim como também, a imigração do pobre europeu, especialmente italianos, que, de certa forma, também almejavam o acesso à terra. Mas sua posse lhe fora antecipadamente dificultada pela lei de 1850. Isto evidenciava que havia um novo segmento de pessoas que também aspirava pela terra como possibilidade de vida. Formava assim um novo grupo social que passou a engrossar e modificar os processos de luta pela terra.

As lutas dos índios já duram tanto quanto a história do país. Negros e índios lutavam contra o cativeiro, na nova ordem estabelecida pela Lei de Terras, a luta era contra o cativeiro da terra, contra a expropriação, contra a expulsão e contra a exclusão, o que marca a história dos trabalhadores desde a luta dos escravos, da luta dos imigrantes, da formação da luta dos camponeses (FERNANDES, 2000, p. 25), do MST (Movimento dos Trabalhadores Rurais Sem Terra), do MCC (Movimento Camponês Corumbiara), do MAB (Movimento dos Atingidos por Barragens), etc.

Os negros entraram na história do país como escravos, e com o advento da República, foi dificultada a eles, a cidadania por falta de uma política que lhe possibilitasse o acesso à terra. Mas eles estão sempre lutando por terra, assim como os imigrantes europeus que também aspiravam à terra. Este foi o caldo dos muitos conflitos que aconteceram no país.

Importante movimento de resistência dos negros foram os quilombos que se formaram no território brasileiro. Os quilombos eram dos mais variados tipos, e o maior deles foi Palmares que resistiu por mais de um século. Palmares era uma outra sociedade que é pouco considerada pelos livros de história e pela história oficial, que é a história da classe dominante, sem povo, sem contexto. A história oficial glorifica Domingos Jorge Velho, o bandeirante que massacrou Palmares e foi o algoz de Zumbi seus pares. 
A República Brasileira já nasceu sob o signo do latifúndio e da "ordem e progresso", inserindo o país no contexto do liberalismo. Essa República, que foi um arranjo entre os latifundiários e os militares, foi sacudida por um dos maiores movimentos de resistência dos trabalhadores: Canudos. Canudos foi combatido pela Igreja, pelos coronéis/latifundiários e pelo Estado positivista. A ordem em Canudos era construir uma comunidade solidária, e o progresso certamente seria o bem estar de todos. Canudos era uma comunidade de lutadores que se negou a sucumbir diante do latifúndio.

A luta dos trabalhadores tem momentos e espaços de maior intensidade como foi Canudos, Contestado, Trombas e Formoso, Corumbiara ${ }^{7}$, Eldorado do Carajás, que fazem parte da luta pela terra e pela liberdade (OLIVEIRA, 1996, p. 13). Oliveira diz que são memórias da capacidade de resistência e de contestação da expropriação, e são também memórias da capacidade destruidora do capital e dos capitalistas.

O modelo de desenvolvimento do país, especialmente o que se refere ao campo, como no processo de modernização da agricultura, é gerador de concentração e exclusão. A estratégia da modernização adotada foi claramente conservadora, e teve como objetivo básico o aumento da produção e da produtividade da terra e do trabalho. A forma foi uma renovação tecnológica com utilização de equipamentos, insumos, técnicas e métodos modernos, e o emprego mínimo de mão-de-obra, com tendência à especialização da mesma. Não se modificou a estrutura fundiária, pelo contrário, a opção foi pelo modelo concentrador ${ }^{8}$. A opção por este modelo começou a ser implantada a partir de 1950, principalmente com a triticultura e, posteriormente, com a soja, cujo incremento de cultivo se deu na década de 1970, coincidindo com as crises do petróleo, quando o país necessitava de novos produtos para o equilíbrio da balança de pagamentos. No mesmo período, houve um avanço também nas lavouras de cana-de-açúcar para a produção de combustível alternativo, e esses cultivos, altamente capitalizados e multiplicadores de capital, se expandiram pelas regiões centrais do país, em substituição a cultivos tradicionais ou mesmo ocupando áreas de cerrados, incorporando estas novas terras ao processo capitalista, modificando ecossistemas, destruindo veredas, contaminando mananciais, erodindo longas extensões de solos, e alterando completamente as paisagens com os "mares de soja".

A expansão territorial da modernização se fez em ondas concêntricas a partir do Centro-Sul e atingiu, de forma diferenciada, os diversos segmentos sociais, desencadeando um movimento migratório de dois tipos distintos. O primeiro movimento, que atingiu um número maior de pessoas, foi 
constituído pelos que ficaram marginalizados do processo produtivo que se instalava: foram os posseiros, empregados e pequenos proprietários que ficaram alijados do contexto modernizante. O segundo movimento, ou segmento social que se deslocou, foi o dos empresários bem sucedidos. Estes, após verem diminuir suas possibilidades de expansão no lugar de origem, estavam aptos a "ocupar" outras áreas onde as terras eram mais baratas, e onde podiam expandir seus empreendimentos e estendê-los sobre terras indígenas e de posseiros em um processo predatório com total apoio do Estado. Normalmente tais empresários dispunham de vultoso capital financeiro e know how aliados a uma legislação agrária e agrícola que incentiva e privilegia a grande produção, principalmente a destinada a exportação? .

A partir de 1965, no Brasil, foram introduzidas novas variedades de trigo, arroz e milho. Os produtores foram induzidos a usar novas técnicas de "correção" dos solos, fertilizantes, combate às pragas e doenças, assim como utilizar equipamentos e técnicas mais modernas, cujo mercado produtor estava em plena expansão ${ }^{10}$, caracterizando a articulação dos espaços monopolistas. O resultado inicial foi o controle sobre os produtores rurais, a introdução de novas culturas, de técnicas de cultivo e manuseio do solo, e uma reorientação alimentar, integrando ao modelo econômico/agrícola internacional. Foi constituído também um embate ideológico, legitimando o moderno contra o atrasado, o "moderno" contra o "arcaico" modo de produzir e de viver do homem do campo. Há um processo artificial de valorização do urbano e a desvalorização do roceiro e da roça ofuscado pelo "fascínio" urbano.

O Brasil confirmou sua opção pelo modelo modernizante internacional ao fazer, entre outras iniciativas, uma legislação compatível com tal opção. Destaque para o Estatuto do Trabalhador Rural de 1963 que, de certa forma, estendia os benefícios sócio-trabalhistas dos operários urbanos aos trabalhadores rurais ${ }^{11}$. Embora tal legislação tenha sido pouco eficaz no que se referia aos benefícios para o trabalhador, foi uma pretensa valorização do trabalhador do campo e a legitimação de novas relações sociais, no entanto, o instrumento mais específico para o avanço da modernização conservadora foi, sem dúvida, o Estatuto da Terra de 1964, cuja letra sugeria, inclusive, reforma agrária, mas cujo espírito era tão somente fortalecer e legitimar o poder dos empresários rurais. Nesse sentido, o Estatuto foi muito eficiente, pois possibilitou a implantação das empresas rurais, criando os instrumentos eficazes para garantir maior articulação do processo produtivo e expansão do latifúndio. Todos estes mecanismos institucionais colaboraram no sentido 
de viabilizar a opção modernizadora altamente excludente. O Estatuto da Terra vinha para burocraticamente viabilizar a modernização da agricultura e reprimir as lutas dos trabalhadores.

Em 1964, o golpe militar tentou golpear também a resistência dos trabalhadores, caçando, matando e "sumindo" com as lideranças em uma tentativa de destruir qualquer movimento que questionasse o regime. Os latifundiários que apoiaram a ditadura militar desde o nascedouro, se fortaleceram legalmente, legitimados pelo Estatuto da Terra. O Estatuto, segundo Oliveira, foi uma espécie de bandeira militar levada ao campo em luta para, através da guerra, impor a "paz na terra".

O regime militar, com seus AI1, AI5 e outras arbitrariedades, embora tenha conseguido calar, literalmente, muitas vozes, não conseguiu impedir que os camponeses continuassem sua luta na sua trajetória de liberdade.

Conflitos por terra surgiram em muitos lugares do Brasil e foram crescentes as tensões sociais, especialmente na Amazônia, relacionadas diretamente à natureza das migrações produzidas pela estrutura fundiária. Martins constatou:

Fala-se muito da concentração da propriedade da terra como um dos fatores da violência, o que é verdade. O recenseamento de 1980 revelou que $45 \%$ das terras do país estavam concentradas em menos de $1 \%$ dos estabelecimentos rurais e que metade dos estabelecimentos, que garantem a maior parte da produção, tinham apenas $2,4 \%$ da terra. O Estatuto da Terra, implantado pela ditadura militar, teria a suposta finalidade de resolver esse problema, se redistribuísse as terras dos grandes proprietários, como ocorreu em outros países, mas dando preferência aos pequenos agricultores sem-terra na ocupação de novas terras das regiões da Amazônia. No entanto, aconteceu o contrário. Antes do golpe militar, entre 1950 e 1960, as terras novas foram ocupadas do seguinte modo: 85\% para estabelecimentos com menos de 100 ha e $15 \%$ para estabelecimentos com mais de 100 ha. Já na vigência do Estatuto, entre 1960 e 1970, essa distribuição de terras novas sofreu modificações, beneficiando os grandes proprietários: $35 \%$ dessas terras foram para os pequenos e 65\% para os grandes. Entre 1970 e 1980, a década da grande violência no campo, os pequenos receberam $6 \%$ das terras novas e os grandes ficaram com 94\%. (MARTINS, 1986, p. 48 e 49).

A “Nova República” (1985) já nasceu velha, velha e rançosa, pois a nova "arrumação" do poder continuou calcada na influência dos latifundiários que para legitimar a violência no campo criaram a União Democrática Ruralista (UDR) para contrapor ao MST e à maioria da sociedade, na Constituinte. A UDR, gestada quando Iris Rezende era Ministro da Agricultura, 1985, teve como seu primeiro presidente o médico ortopedista Ronaldo 
Caiado. Este deputado federal votou contra o impeachment de Collor e faz parte de uma sangrenta oligarquia agrária de Goiás (SILVA, 1991, p. 47). A UDR utilizava uma retórica modernista, em um fantástico poder midiático que o dinheiro lhe conferia, procurava convencer até pequenos produtores a empunhar a bandeira da integridade pessoal, a propriedade, a moral e contra a corrupção.

A UDR prosperou rapidamente e atingiu o seu principal objetivo, que foi interferir na Constituinte, e foi sob esta influência que a proposta de reforma agrária, inserida na Constituição de 1988, não correspondeu aos anseios de milhões de trabalhadores que não puderam "marchar sobre Brasília” para fazer ouvir suas vozes.

Com a criação da UDR, institucionalizou-se o crime no campo, pois foi grande o envolvimento dela com a violência e sua ingerência também na impunidade.

São muitos os movimentos que lutam por terra no país do latifúndio. Uma outra forma de exclusão é o modelo energético brasileiro. O modelo é excludente porque a energia, que deveria ser um bem público, não chega à casa de milhões de brasileiros. É excludente também por provocar a migração compulsória de milhares de trabalhadores que não conseguem refazer suas vidas no campo e menos ainda na cidade, onde são derrotados na luta pelo emprego.

A luta dos atingidos por barragens inicialmente pleiteava indenizações mais juntas a reassentamentos. O surgimento do Movimento dos Atingidos por Barragens (MAB) serviu para unificar estas lutas, e o enfretamento, que antes era contra o Estado, hoje é contra os conglomerados econômicos que privatizaram o Estado brasileiro através da privatização da energia e da água.

Se tem havido conflitos no campo é porque, de certa forma, está havendo reação por parte dos que estão sofrendo violência. São muitos os sujeitos da luta secular no campo brasileiro: as nações indígenas e a luta pela demarcação dos seus territórios; os posseiros em luta pela terra de trabalho; os peões lutando contra a peonagem; os camponeses enfrentando as desapropriações nas grandes obras do Estado; como exemplo, a luta contra a construção das barragens; o movimento dos camponeses contra a subordinação da indústria; o movimento dos "brasiguaios"; o movimento dos bóiasfrias; o sindicalismo no campo; e o movimento dos trabalhadores sem terra, mostrando que os campos de luta são muitos, as estratégias de resistência são diversificadas, mas todos estão lutando contra as injustiças do latifúndio 

acesso e permanência na terra.

\section{Nota}

1 Saga da Amazônia. CD Cantoria.

2 MARTINS, José de Souza. Revisando a questão agrária. In boletim do militante, $\mathrm{n}^{\circ}$ 27, dezembro/96. p. 30-57.

3 Prof. Dr. Bernardo Mançano Fernandes. UNESP, Presidente Prudente.

4 Folha de São Paulo, 02/01/2000. Brasil 1-11.

5 Em 14/7/1995 cerca de 600 famílias ocuparam a fazenda Santa Elina no município de Corumbiara, Rondônia. Rapidamente a justiça expediu a liminar de manutenção de posse em favor do fazendeiro e o juiz encaminhou ofício ao comando da PM exigindo a IMEDIATA retirada dos posseiros. No dia 9 de agosto a liminar foi cumprida, resultando em um dos maiores massacres da história recente do país. Houve, então, grande repercussão do fato nos noticiários nacionais e internacionais. Logo depois, a própria mídia foi, aos poucos, apagando Corumbiara dos noticiários e da memória dos brasileiros. Mas as marcas de Corumbiara estarão naqueles corpos, naquelas almas e naquele chão, para sempre.

6 "Da Senzala à Colônia” e "Da Monarquia à República”.

7 Na edição renovada de "A Geografia das Lutas no Campo" o autor acrescenta uma parte sobre o Massacre de Corumbiara.

8 O processo de modernização da agricultura, no Brasil, foi importante no sentido do deslocamento de população e prosseguimento do modelo político concentrador da renda e de terras.

Onde estariam os camponeses que perderam suas terras? Alguns se tornaram empregados dos latifundiários, outros foram para a cidade "tentar a sorte" e certamente milhares estão engrossando o movimento dos que lutam por terra.

9 Em Rondônia isto fica muito claro, visto que os camponeses tiveram dificuldade em entrar na terra e mais dificuldades ainda em se manter na terra. E os empresários rurais expandem, não tanto seus empreendimentos produtivos, mas suas áreas de especulação.

$10 \mathrm{O}$ mercado produtor de implementos e equipamentos agrícolas norte-americano estava em franca expansão, então há uma sincronia entre a produção e a criação de um mercado consumidor de tais produtos no Brasil.

11 O Estatuto gerou, em muitos lugares, a expulsão dos trabalhadores que viviam na condição de moradores e agregados. Os proprietários trataram logo de "acertar" as contas com os trabalhadores nessas condições com a justificativa de que eles poderiam "adquirir direitos" e viriam a ser uma ameaça à propriedade, com possibilidade de pleitear na justiça a posse daquele lugar onde estava a casa, o quintal, a horta, enfim, aquele pedacinho da roça na qual moravam há muitos anos. 


\section{Referências}

BUCCI, E. O Peixe morre pela boca. São Paulo: Página Aberta Ltda, 1993.

CÂMARA DOS DEPUTADOS. Tribunal Internacional. Julgamento dos Massacres de Eldorado dos Carajás e Corumbiara: Comissão de Direitos Humanos, Centro de Documentação e Informação - Coordenação de publicações, Brasília, 1997.

CHAUI, M. Brasil: mito fundador e sociedade autoritária. São Paulo: Fundação Perseu Abramo, 2000.

COSTA, E. V. da. Da Senzala à Colônia. São Paulo: Editora Ciências Humanas, 1982.

COSTA, E. V. da. Da Monarquia à República: Momentos Decisivos. 6ª ed., São Paulo: Brasiliense, 1994.

CPT (Comissão Pastoral da Terra), (94, 95, 96, 97, 98 e 99). Conflitos no Campo Brasil.Goiânia. FERNANDES, B. M. A Formação do MST no Brasil. Petrópolis: Vozes, 2000.

GONÇALVES, C. W.P. Paixão da terra: ensaios críticos de ecologia e geografia. Rio de Janeiro: Rocco Socii, 1984.

GRZYBOWSKI, C. Caminhos e descaminhos dos movimentos sociais no campo. 2ª ed. Petrópolis: Vozes: Fase, 1990.

HOBSBAWM, E. A era dos extremos: o breve século XX 1914-1991. São Paulo: Companhia das Letras, 1997.

IANNI, O. A ditadura do grande capital: civilização brasileira. Rio de Janeiro. 1981.

KAUTSKY, K. A questão agrária. Vol. 1 e 2. Portucalense Editora: Porto. 1972

MARTINS, J. S. A O cativeiro da terra. 4ª ed. São Paulo: Hucitec, 1990.

MARTINS, J. S. A. Os camponeses e a política no brasil: as lutas sociais no campo e o seu lugar no processo político. 3를 ed. Petrópolis: Vozes, 1986.

MARTINS, J. S. A. Revisando a questão agrária. In. Boletim do militante, $\mathrm{n}^{\circ}$ 27, dezembro/96, p 30/57.

MARTINS, J. S. A. A imigração e a crise do brasil agrário. São Paulo: Livraria Pioneira Editora, 1973.

MESQUITA, H. A. de. (2001). Os meninos vão à luta. In: site www.cptnac.com.br.

MESQUITA, H. A. de. Algumas Considerações Acerca da Modernização da Agricultura. Anais: V Encontro APPSA Centro Oeste. Goiânia. 1995

MESQUITA, H. A. de. Corumbiara: O Massacre dos Camponeses. In: Anais do 8o Encuentro de Geógrafos de América Latina. Santiago, 2001.

MOORE. Júnior, B. As origens sociais da ditadura e da democracia - senhores e camponeses na construção do mundo moderno. São Paulo: Martins Fontes, 1983.

OLIVEIRA, A. U. de. A agricultura camponesa no Brasil. São Paulo: Contexto, 1991.

OLIVEIRA, A. U. de. A geografia das lutas no campo. São Paulo: Contexto, 1996. 
SADER, E. Quando novos personagens entraram em cena. São Paulo: Paz e Terra.

SADER, M. R. C. de T. Espaço de luta no Bico do Papagaio. Tese de Doutorado. FFLCH/USP. São Paulo (mimeo). 1986

SANTOS, M. Espaço e método. São Paulo: Nobel, 1988.

SHANIN, T. La classe incômoda. Madrid: Alianza Editorial,1993.

SILVA, E. I. da. A região como resultado de múltiplos processos. In: Boletim Goiano de Geografia. 1991, Cegraf/UFG. Vol. 11. № 1. Jan/Dez.

Helena Angélica - Professora Adjunta do Curso de Geografia CAC/UFG - Coordenadora do grupo de pesquisa: Geografia, Trabalho e Movimentos Sociais (GETeM)

Recebido para publicação em março de 2008 Aceito para publicação em abril de 2008 